\title{
Understanding A-type supergiants
}

\section{Ultraviolet and visible spectral atlas ${ }^{\star}$ of A-type supergiants, ${ }^{\star \star}$}

\author{
E. Verdugo ${ }^{1}$, A. Talavera ${ }^{2}$, and A.I. Gómez de Castro ${ }^{3}$ \\ 1 ISO Data Centre, P.O. Box 50727, E-28080-Madrid, Spain \\ e-mail: everdugo@iso.vilspa.esa.es \\ 2 LAEFF/INTA, P.O. Box 50727, E-28080-Madrid, Spain \\ e-mail: ati@laeff.esa.es \\ 3 Instituto de Astronomía y Geodesia (CSIC-UCM), Fac. cc. Matemáticas, Universidad Complutense, Av. Complutense s/n, \\ E-28040-Madrid, Spain \\ e-mail: aig@orion.mat.ucm.es
}

Received October 14, 1997; accepted April 12, 1999

\begin{abstract}
This paper is the first of a series whose aim is to perform a systematic study of A-type supergiant atmospheres and winds. Here we present a spectral atlas of 41 A-supergiants observed by us in high and medium resolution in the visible and ultraviolet. The atlas consists of profiles of the $\mathrm{H} \alpha, \mathrm{H} \beta, \mathrm{H} \gamma, \mathrm{H} \delta, \mathrm{H} \epsilon$, Ca II ( $\mathrm{H}$ and $\mathrm{K}$ ), Na I (D1 and D2), Mg II $4481, \mathrm{Mg}$ II [uv1] and Fe II [uv1, uv2, uv3, uv62, uv63, uv161] lines for 41 stars with spectral types ranging from B9 to A9 and luminosity classes Ia, Iab and Ib, and provides the basic data for a thoughtful study of these stars. The overall characteristics of the sample as well as the data reduction procedures are described. We also present some examples of spectral variability.
\end{abstract}

Key words: atlases — line: profiles — stars: supergiants ultraviolet: stars

\section{Introduction}

Mass loss is ubiquitous among highly luminous OBA stars. The last decade has seen an enormous increase in the

Send offprint requests to: E. Verdugo

* Figures 1-3 are only available in electronic form at the http://www.edpsciences.com

** Based on observations made with the INT and JKT telescopes operated on the island of La Palma by the RGO in the Spanish Observatorio del Roque de Los Muchachos of the Instituto de Astrofisica de Canarias, with the $2.2 \mathrm{~m}$ telescope at Calar Alto Observatory, Spain, with the Bernard Lyot $2 \mathrm{~m}$ telescope at Pic Du Midi Observatory, France and observations collected at the European Southern Observatory at La Silla, Chile. number and the quality of the observational studies of stellar winds. At the same time the theory of stellar winds has been improved dramatically. However most of this work has been limited to $\mathrm{O}$ and $\mathrm{B}$ stars. To date, very few studies have been devoted to A-type supergiants. These stars occupy a region of the HR diagram where evolution is rapid and therefore they are few in number. Furthermore, the indicators of stellar winds are significantly weaker in A-supergiants than in OB supergiants. Nevertheless it is known from the few A supergiants studied that the structure of their stellar wind is unique in some way that is not yet understood.

There are no comprehensive studies of the line profiles formed in the winds of these stars, of which only a few have been studied in detail. In the optical, a photographic survey of $\mathrm{H} \alpha$ emission in luminous $\mathrm{O} 9$ to A5 stars was undertaken by Rosendhal (1973) showing the strong influence of luminosity upon the $\mathrm{H} \alpha$ profile in late-B and $\mathrm{A}$ supergiants. The emission at $\mathrm{H} \alpha$ disappears for stars fainter than absolute visual magnitude -6.8 to -7.0 , while at the highest luminosities emission dominates over absorption. In the ultraviolet, where most of the indicators of mass loss are observed, the UV P Cygni profiles for O and early $\mathrm{B}$ stars have been studied by a large number of authors. However the UV spectra of A-supergiants have scarcely been examined (e.g. Lamers et al. 1995; Lamers et al. 1978; Praderie et al. 1980; Underhill \& Doazan 1982; Hensberge et al. 1982); the most extensive study was performed by Talavera \& Gómez de Castro (1987) from the high resolution data available in the International Ultraviolet Explorer (IUE) satellite archive. They found two different groups of A-supergiants: stars showing spectral lines characteristic of mass outflow and stars which do not show any sign of stellar winds in their spectrum. The mass-losing 
Table 1. Basic properties of the program stars

\begin{tabular}{|c|c|c|c|c|c|c|c|c|}
\hline \multicolumn{2}{|c|}{ Star } & \multicolumn{2}{|c|}{ Position (2000.0) } & \multirow[t]{2}{*}{$m_{v}$} & \multirow[t]{2}{*}{$M_{v}$} & \multirow[t]{2}{*}{ OB Assoc. } & \multicolumn{2}{|c|}{ Available data } \\
\hline $\mathrm{HD} / \mathrm{BD}$ & Other name & $\alpha$ & $\delta$ & & & & Visible & IUE \\
\hline $\mathrm{BD}+6051$ & SAO 11196 & 002633.7 & +612446 & 9.23 & -4.80 & Cas OB4 & $\mathrm{Y}$ & $\mathrm{N}$ \\
\hline HD 2928 & SAO 11258 & 003313.3 & +623214 & 8.61 & -5.50 & Cas OB4 & $\mathrm{Y}$ & $\mathrm{Y}$ \\
\hline HD 3940 & SAO 11343 & 004250.0 & +641728 & 7.26 & -6.37 & Cas OB7 & $\mathrm{Y}$ & $\mathrm{Y}$ \\
\hline $\mathrm{BD}+61153$ & SAO 11344 & 004259.1 & +621406 & 9.32 & -4.69 & Cas OB7 & $\mathrm{Y}$ & $\mathrm{N}$ \\
\hline HD 4717 & SAO 11421 & 005016.1 & +631017 & 8.9 & -5.90 & Cas OB7 & $\mathrm{Y}$ & $\mathrm{N}$ \\
\hline HD 5776 & SAO 11519 & 010032.8 & +630144 & 8.05 & -4.97 & Cas OB7 & $\mathrm{Y}$ & $\mathrm{Y}$ \\
\hline HD 12953 & V472 Per & 020840.4 & +582525 & 5.67 & -7.81 & Per OB1 & $\mathrm{Y}$ & $\mathrm{Y}$ \\
\hline HD 13476 & HR 641 & 021341.5 & +583339 & 6.44 & -7.10 & Per OB1 & $\mathrm{Y}$ & $\mathrm{Y}$ \\
\hline HD 13744 & SAO 23101 & 021558.5 & +581737 & 7.59 & -6.46 & Per OB1 & $\mathrm{Y}$ & $\mathrm{Y}$ \\
\hline HD 14433 & SAO 23243 & 022155.3 & +571434 & 6.39 & -6.89 & Per OB1 & $\mathrm{Y}$ & $\mathrm{Y}$ \\
\hline HD 14489 & i Per & 022221.3 & +555044 & 5.20 & -7.84 & Per OB1 & $\mathrm{Y}$ & $\mathrm{Y}$ \\
\hline HD 14535 & SAO 23263 & 022253.4 & +571442 & 7.44 & -6.50 & Per OB1 & $\mathrm{Y}$ & $\mathrm{Y}$ \\
\hline HD 15316 & SAO 23374 & 022958.6 & +574915 & 7.23 & -6.48 & Per OB1 & $\mathrm{Y}$ & $\mathrm{Y}$ \\
\hline HD 16778 & SAO 23564 & 024353.5 & +594922 & 7.71 & -6.89 & Per OB1 & $\mathrm{Y}$ & $\mathrm{Y}$ \\
\hline HD 236995 & SAO 23582 & 024503.4 & +583305 & 8.63 & -4.77 & Per OB1 & $\mathrm{Y}$ & $\mathrm{N}$ \\
\hline HD 17378 & V480 Per & 024930.6 & +570503 & 6.25 & -7.81 & Per OB1 & $\mathrm{Y}$ & $\mathrm{Y}$ \\
\hline HD 20041 & HR 964 & 031547.9 & +570826 & 5.79 & -6.60 & Cam OB1 & $\mathrm{Y}$ & $\mathrm{Y}$ \\
\hline HD 21389 & HR 1040 & 032954.7 & +585243 & 4.54 & -7.10 & Cam OB1 & $\mathrm{Y}$ & $\mathrm{Y}$ \\
\hline HD 46300 & 13 Mon & 063254.2 & +071959 & 4.50 & -4.80 & Mon OB1 & $\mathrm{Y}$ & $\mathrm{Y}$ \\
\hline HD 59612 & HR 2874 & 072951.4 & -230128 & 4.85 & -5.10 & - & $\mathrm{Y}$ & $\mathrm{Y}$ \\
\hline HD 87737 & $\eta$ Leo & 100719.9 & +164545 & 3.52 & -5.30 & Sco-Cen & $\mathrm{N}$ & $\mathrm{Y}$ \\
\hline HD 92207 & V370 Car & 103727.0 & -584360 & 5.46 & -8.00 & Car OB1 & $\mathrm{N}$ & $\mathrm{Y}$ \\
\hline HD 100198 & V809 Cen & 113115.0 & -611642 & 6.31 & -7.20 & Car-Cen & $\mathrm{N}$ & $\mathrm{Y}$ \\
\hline HD 100826 & SAO 251469 & 113542.3 & -611716 & 6.29 & -5.40 & NGC 3766 & $\mathrm{~N}$ & $\mathrm{Y}$ \\
\hline HD 102878 & HR 4541 & 115027.2 & -623857 & 5.70 & -7.00 & Cru OB1 & $\mathrm{Y}$ & $\mathrm{Y}$ \\
\hline HD 103516 & HR 4563 & 115459.9 & -631644 & 5.90 & -4.90 & Car-Cen & $\mathrm{N}$ & $\mathrm{Y}$ \\
\hline HD 104035 & HR 4578 & 115847.7 & -642021 & 5.61 & -5.20 & Car-Cen & $\mathrm{N}$ & $\mathrm{Y}$ \\
\hline HD 104111 & SAO 251670 & 115925.6 & -624951 & 6.37 & - & - & $\mathrm{N}$ & $\mathrm{Y}$ \\
\hline HD 161912 & iot02 Sco & 175011.0 & -400525 & 4.81 & -4.70 & - & $\mathrm{N}$ & $\mathrm{Y}$ \\
\hline HD 187983 & HR 7573 & 195201.4 & +245932 & 5.57 & -6.50 & Vul OB4 & $\mathrm{Y}$ & $\mathrm{N}$ \\
\hline HD 197345 & $\alpha$ Cyg & 204125.8 & +451649 & 1.25 & -8.55 & Cyg OB7 & $\mathrm{Y}$ & $\mathrm{Y}$ \\
\hline HD 207260 & $\nu$ Cep & 214526.9 & +610715 & 4.30 & -6.82 & Cep OB2 & $\mathrm{Y}$ & $\mathrm{Y}$ \\
\hline HD 207673 & HR 8345 & 214940.0 & +410856 & 6.48 & -4.97 & - & $\mathrm{Y}$ & $\mathrm{Y}$ \\
\hline HD 209900 & SAO 34034 & 220513.7 & +533037 & 8.71 & -4.85 & Cep OB1 & $\mathrm{Y}$ & $\mathrm{N}$ \\
\hline HD 210221 & HR 8443 & 220725.5 & +531827 & 6.14 & -5.00 & Cep OB1 & $\mathrm{Y}$ & $\mathrm{Y}$ \\
\hline HD 211971 & SAO 34314 & 221925.6 & +600852 & 6.90 & -5.50 & Cep OB2 & $\mathrm{Y}$ & $\mathrm{Y}$ \\
\hline HD 212593 & $4 \mathrm{Lac}$ & 222430.9 & +492835 & 4.56 & -5.86 & Lac OB1 & $\mathrm{Y}$ & $\mathrm{Y}$ \\
\hline HD 213470 & SAO 34531 & 223018.6 & +571332 & 6.65 & -7.09 & Cep OB1 & $\mathrm{Y}$ & $\mathrm{Y}$ \\
\hline $\mathrm{BD}+602542$ & SAO 20639 & 232705.6 & +612242 & 8.82 & -5.09 & Cas OB2 & $\mathrm{Y}$ & $\mathrm{N}$ \\
\hline HD 223385 & 6 Cas & 234850.1 & +621252 & 5.43 & -8.22 & Cas OB5 & $\mathrm{Y}$ & $\mathrm{Y}$ \\
\hline HD 223960 & SAO 20923 & 235349.9 & +605113 & 6.93 & -6.90 & Cas OB5 & $\mathrm{Y}$ & $\mathrm{Y}$ \\
\hline
\end{tabular}

Note: $\mathrm{Y} \equiv$ Observed.

$\mathrm{N} \equiv$ Not observed.

stars showed absorption shortward shifted components in the Mg II, Fe II, C II, Si II and Al II lines. Moreover these components are variable, as well as the terminal velocity measured from the violet edge of the resonance $\mathrm{Mg}$ II lines. Contrary to the relation found by Abbot (1978) for radiatively driven winds in OB supergiants, Talavera \& Gómez de Castro (1987) found that the measured terminal velocity in A-supergiants decreases as the escape velocity increases. Therefore the radiation driven wind theory seems to be not applicable to A-supergiants. However, the latest theoretical progress on this point (Achmad et al. 1997; McCarthy et al. 1997; Kudritzki et al. 1997) has begun to clarify such discrepancies in the radiatively driven wind theory frame.

Mass loss from early type stars is due to radiation pressure on UV lines, although a detailed comparison of the predicted and observed mass loss rates of OB stars shows 
Table 2. Spectral types

\begin{tabular}{|c|c|c|c|c|c|c|c|}
\hline \multirow[t]{2}{*}{ Star } & \multicolumn{7}{|c|}{ Spectral Type from different sources } \\
\hline & $(\mathrm{Hu})$ & $(\mathrm{GS})$ & $(\mathrm{Bw})$ & $(\mathrm{Fn})$ & $(\mathrm{KG})$ & $(\mathrm{Cz})$ & $(\mathrm{St})$ \\
\hline $\mathrm{BD}+6051$ & $\mathrm{~A} 2 \mathrm{Ib}$ & & & & & & \\
\hline HD 2928 & A0 Iab & & & & & & \\
\hline HD 3940 & A1 Ia & A1 Ia & & & & & \\
\hline $\mathrm{BD}+61153$ & A0 Ib & $\mathrm{A} 0 \mathrm{Ib}$ & & & & & \\
\hline HD 4717 & A0 Ib & & & & & & \\
\hline HD 5776 & $\mathrm{~A} 0 \mathrm{Ib}$ & $\mathrm{A} 0 \mathrm{Ib}$ & & & & & \\
\hline HD 12953 & A1 Ia & A1 Ia & & A1 Ia & & & \\
\hline HD 13476 & A3 Iab & A3 Iab & A3 Iab & & & & \\
\hline HD 13744 & A0 Iab & A0 Iab & B9 Iab & & & & \\
\hline HD 14433 & A1 Ia & A1 Ia & & & & & \\
\hline HD 14489 & A2 Ia & A2 Iabs & A3 Ia & & & & \\
\hline HD 14535 & A2 Iap & A2 Iabs & & & & & \\
\hline HD 15316 & A3 Iab & $\mathrm{A} 2 \mathrm{Ia}$ & A2 Iab & & & & \\
\hline HD 16778 & A2 Ia & A2 Ia & A1 Ia & & & & \\
\hline HD 236995 & A0 Ib & A0 Ib & & & & & \\
\hline HD 17378 & A5 Ia & A5 Ia & A3 Ia-Iab & & & & \\
\hline HD 20041 & A0 Ia & & B9.5 Ia & & & & \\
\hline HD 21389 & A0 Ia & & A0 Ia & & & & \\
\hline HD 46300 & A0 Ib & $\mathrm{A} 0 \mathrm{Ib}$ & $\mathrm{A} 1 \mathrm{Ib}$ & $\mathrm{A} 0 \mathrm{Ib}$ & & & \\
\hline HD 59612 & A5 Ib & & A5 Ib-II & A5 Ib & & & \\
\hline HD 87737 & A0 Ib & & A0 Iab & A0 Ib & & & \\
\hline HD 92207 & A0 Ia & & & A0 Ia & & & \\
\hline HD 100198 & & & & A3 Ia & & & \\
\hline HD 100826 & & & & A0 Ia & & & $\mathrm{A} 0 \mathrm{Ib}$ \\
\hline HD 102878 & A2 Ia-Iab & & & & A2 Ia & & \\
\hline HD 103516 & A3 Ib & & & B9 II & & & \\
\hline HD 104035 & A3 Ib & & & A3 Ib & & & \\
\hline HD 104111 & & & & A9 Ib/II & & & \\
\hline HD 161912 & $\mathrm{~A} 2 \mathrm{Ib}$ & & & & & & \\
\hline HD 187983 & A1 Iab & & & A1 Iab & & & \\
\hline HD 197345 & A 2 Ia & A2 Ia & A0 Ia & & & & \\
\hline HD 207260 & A2 Iab & A2 Ia & A5 Ia & & & & \\
\hline HD 207673 & & & A1 Iab & & & $\mathrm{A} 2 \mathrm{Ib}$ & \\
\hline HD 209900 & A0 Ib & A0 Ib & & & & & \\
\hline HD 210221 & & & A3 Ib & & & & \\
\hline HD 211971 & $\mathrm{~A} 2 \mathrm{Ib}$ & & $\mathrm{A} 1 \mathrm{Ia}$ & & & & \\
\hline HD 212593 & B9 Iab & & B9 Ia & & & & \\
\hline HD 213470 & A3 Ia & A3 Ia & A3 Ia & & & & \\
\hline $\mathrm{BD}+602542$ & $\mathrm{~A} 2 \mathrm{Ib}$ & $\mathrm{A} 2 \mathrm{Ib}$ & & & & & \\
\hline HD 223385 & A3 Ia & A3 Ia & & & & & \\
\hline HD 223960 & $\mathrm{~A} 0 \mathrm{Ia}+$ & $\mathrm{A} 0 \mathrm{Ia}+$ & & & & & \\
\hline
\end{tabular}

References:

(Hu) Humphreys (1978).

(Fn) Fernie (1983).

(GS) Garmany \& Stencel (1992).

(KG) Kaltcheva \& Georgiev (1994).

(Bw) Bouw (1981).

(Cz) Cananzi et al. (1993).

(St) Stothers (1991). 
systematic differences. Such a comparison has not been made for A-supergiants. Moreover for the few studied, the mass loss rates derived from the UV lines are significantly lower, by a factor $10^{-1}$ to $10^{-2}$, than the rates derived from $\mathrm{H} \alpha$ (Praderie et al. 1980; Hensberge et al. 1982; Kunasz \& Morrison 1982). Another source of discrepancy is the problem of the superionization of the wind of earlytype stars (Lamers \& Snow 1978; Cassinelli et al. 1978; Groenewegen \& Lamers 1991; Owocki 1992). There is as yet no study of the presence or absence of superionization in the winds of A supergiants.

We have selected 41 A-type supergiants to carry out a systematic study of stellar wind indicators in these stars in the visible and ultraviolet. In this atlas we show the profiles of the $\mathrm{H} \alpha, \mathrm{H} \beta, \mathrm{H} \gamma, \mathrm{H} \delta, \mathrm{H} \epsilon$ Balmer lines, the $\mathrm{Ca}$ II $\mathrm{H}$ and $\mathrm{K}$ lines, the $\mathrm{Na} \mathrm{I} \mathrm{D}$ lines, $\mathrm{Mg} \mathrm{II}_{4481}, \mathrm{Mg}$ II [uv1] and Fe II [uv1, uv2, uv3, uv62, uv63, uv161] for the program stars, as well as some relevant examples of the variations in the profiles.

The A-supergiants sample is presented in Sect. 2. The observations and the data reduction techniques are described in Sect. 3. The spectral atlas is introduced in Sect. 4 and a brief summary is provided in Sect. 5 .

A detailed analysis of these data and their implications for the understanding of A-type supergiants will be published in a series of forthcoming papers (Verdugo et al. 1999).

\section{The program stars}

The stars selected belong to OB associations or clusters, so that we have a good estimate of the distance and therefore of the absolute magnitude. We have used the catalogue of Garmany \& Stencel (1992) which is largely based on the cluster distances obtained by Humphreys (1978). In these catalogues the sample is biased towards early A-type supergiants. We have tried hard to get a good sample of all the luminosity classes for each spectral type since we expect significant luminosity effects in the lines formed in the wind. The whole sample is listed in Table 1 ; ordered by right ascension and identified by their entry number in the HD or BD catalogues. Another usual identification (as the SAO number or the variable star name) is provided in the second column. The equatorial coordinates $(\alpha(2000.0), \delta(2000.0))$ are given in the third and fourth column. The apparent visual magnitudes are listed in the fifth column. The absolute visual magnitude and the OB associations to which each of the stars belongs are given in the sixth and seventh columns respectively. The absolute magnitudes come from the catalogues cited above and they are calculated from the adopted distance to the association.

Most of the stars have been observed both in the ultraviolet and visible, although the less luminous stars could not be observed with the IUE satellite and only two south-
Table 3. Observed spectral ranges

\begin{tabular}{lccc}
\hline Campaign & $\begin{array}{c}\text { Central } \lambda \\
(\AA)\end{array}$ & $\begin{array}{c}\Delta \lambda \\
(\AA)\end{array}$ & $\begin{array}{c}\text { Dispersion } \\
(\AA / \text { pixel })\end{array}$ \\
\hline La Palma (INT) & 3951 & 96 & 0.166 \\
& 4481 & 97 & 0.168 \\
& 5889 & 62 & 0.107 \\
& 6563 & 100 & 0.173 \\
\hline La Palma (JKT) & 4300 & 400 & 0.39 \\
& 4800 & 350 & 0.34 \\
& 6200 & 650 & 0.63 \\
& 6678 & 820 & 0.80 \\
\hline Calar Alto (2.2 m) & 3950 & 131 & 0.128 \\
& 4481 & 133 & 0.130 \\
& 4861 & 132 & 0.129 \\
& 5889 & 124 & 0.121 \\
& 6562 & 100 & 0.097 \\
\hline
\end{tabular}

ern stars were observed in the visible. We summarize this information in the last two columns of Table 1.

In Table 2 we give the tabulated spectral types of each star taken from the literature (Humphreys 1978; Garmany \& Stencel 1992; Bouw 1981; Fernie 1983; Stothers 1991; Kaltcheva \& Georgiev 1994; Cananzi et al. 1993).

\section{Observations and data reduction}

\subsection{Visible data}

\subsubsection{Observations}

We have carried out four different visible campaigns to observe the $\mathrm{H} \alpha, \mathrm{H} \beta, \mathrm{H} \gamma, \mathrm{H} \delta$ and $\mathrm{H} \epsilon$ Balmer lines, Ca II $\mathrm{H}$ and $\mathrm{K}, \mathrm{Na}$ I D and Mg II $\lambda 4481 \AA$ lines. The observed spectral ranges are listed in Table 3 . We summarize in Table 4 the information available for each star as well as the instrumental set-up (telescope+spectrograph) used to obtain the data and the Julian date of the observations.

The first campaign was carried out in September 1988 with the Isaac Newton Telescope of the Roque de los Muchachos Observatory in La Palma. All the spectra were taken with the Intermediate Dispersion Spectrograph (IDS) equipped with a GEC CCD which has $22 \mu \mathrm{m}$ pixels arranged in an $578 \times 385$ array. We observed $\mathrm{H} \alpha$, Ca II $\mathrm{H}$ and $\mathrm{K}, \mathrm{Na} \mathrm{I} \mathrm{D}$ and the $\mathrm{Mg} \mathrm{II}_{4481}$ lines with a resolving power around 16500 .

The second campaign (October 1988) was carried out with the Coudé Spectrograph (resolving power around 26000) of the $2.2 \mathrm{~m}$ telescope at the Calar Alto Observatory. The detector used was an RCA CCD $(1024 \times 656,15 \mu$ pixels $)$. We obtained the $\mathrm{H} \alpha, \mathrm{H} \beta$, $\mathrm{Ca} \mathrm{II}(\mathrm{H}, \mathrm{K})$ and $\mathrm{Mg} \mathrm{II}_{4481}$ profiles.

The third campaign was carried out in the Pic Du Midi Observatory (France) in August 1994. We used the MUSICOS (for MUlti-SIte COntinuous Spectroscopy) 
Table 4. Journal of observations in the visible

\begin{tabular}{|c|c|c|c|c|c|c|c|}
\hline STAR & Sp. Range & Tel. & JD-2440000. & STAR & Sp. Range & Tel. & JD-2440000. \\
\hline \multirow[t]{3}{*}{$\mathrm{BD}+6051$} & $\mathrm{H} \alpha$ & INT & $7432.45,7434.45$ & \multirow[t]{9}{*}{ HD 14433} & $\mathrm{H} \alpha$ & INT & $7431.63,7433.67$ \\
\hline & $\mathrm{NaI}+\mathrm{HeI}$ & INT & 7433.57 & & & $\mathrm{CA}$ & 7458.56 \\
\hline & $\mathrm{MgII}+\mathrm{HeI}$ & INT & 7431.54 & & & JKT & $9614.65,9615.61$ \\
\hline \multirow[t]{5}{*}{ HD 2928} & \multirow[t]{2}{*}{$\mathrm{H} \alpha$} & INT & $7432.48,7434.47$ & & CaII & INT & 7432.67 \\
\hline & & JKT & 9615.55 & & & $\mathrm{CA}$ & 7454.55 \\
\hline & $\mathrm{NaI}+\mathrm{HeI}$ & INT & 7433.59 & & $\mathrm{NaI}+\mathrm{HeI}$ & INT & 7434.66 \\
\hline & $\mathrm{H} \beta$ & $\mathrm{CA}$ & 7458.48 & & $\mathrm{H} \beta$ & $\mathrm{CA}$ & 7456.55 \\
\hline & $\mathrm{MgII}+\mathrm{HeI}$ & $\mathrm{CA}$ & 7457.46 & & & JKT & 9616.62 \\
\hline \multirow[t]{8}{*}{ HD 3940} & $\mathrm{H} \alpha$ & INT & $7432.50,7434.50$ & & $\mathrm{MgII}+\mathrm{HeI}$ & INT & 7434.71 \\
\hline & & $\mathrm{CA}$ & 7458.45 & \multirow[t]{10}{*}{ HD 14489} & $\mathrm{H} \alpha$ & INT & $7431.64,7433.68$ \\
\hline & & JKT & $9614.61,9615.54$ & & & $\mathrm{CA}$ & 7458.57 \\
\hline & $\mathrm{NaI}+\mathrm{HeI}$ & INT & 7433.61 & & & JKT & $9614.66,9615.61$ \\
\hline & $\mathrm{H} \beta$ & $\mathrm{CA}$ & 7458.47 & & CaII & INT & 7432.70 \\
\hline & & JKT & 9616.55 & & $\mathrm{NaI}+\mathrm{HeI}$ & INT & 7434.67 \\
\hline & $\mathrm{MgII}+\mathrm{HeI}$ & $\mathrm{CA}$ & 7457.50 & & & JKT & 9621.71 \\
\hline & $\mathrm{H} \gamma+\mathrm{H} \delta$ & JKT & 9621.55 & & $\mathrm{H} \beta$ & $\mathrm{CA}$ & 7456.56 \\
\hline \multirow[t]{3}{*}{$\mathrm{BD}+61153$} & $\mathrm{H} \alpha$ & INT & $7432.51,7434.50$ & & & JKT & 9616.63 \\
\hline & $\mathrm{NaI}+\mathrm{HeI}$ & INT & 7433.62 & & $\mathrm{MgII}+\mathrm{HeI}$ & INT & 7434.73 \\
\hline & $\mathrm{MgII}+\mathrm{HeI}$ & INT & 7431.56 & & $\mathrm{H} \gamma+\mathrm{H} \delta$ & JKT & 9621.59 \\
\hline \multirow[t]{3}{*}{ HD 4717} & $\mathrm{H} \alpha$ & INT & $7432.53,7434.53$ & \multirow[t]{9}{*}{ HD 14535} & $\mathrm{H} \alpha$ & INT & $7432.58,7434.56$ \\
\hline & $\mathrm{NaI}+\mathrm{HeI}$ & INT & 7434.62 & & & $\mathrm{CA}$ & 7458.58 \\
\hline & $\mathrm{MgII}+\mathrm{HeI}$ & $\mathrm{CA}$ & 7457.51 & & & JKT & $9614.66,9615.62$ \\
\hline \multirow[t]{4}{*}{ HD 5776} & $\mathrm{H} \alpha$ & INT & $7432.56,7434.55$ & & $\mathrm{NaI}+\mathrm{HeI}$ & INT & 7434.67 \\
\hline & $\mathrm{NaI}+\mathrm{HeI}$ & INT & 7434.63 & & & JKT & 9621.72 \\
\hline & $\mathrm{H} \beta$ & $\mathrm{CA}$ & 7458.51 & & $\mathrm{H} \beta$ & $\mathrm{CA}$ & 7456.56 \\
\hline & $\mathrm{MgII}+\mathrm{HeI}$ & $\mathrm{CA}$ & 7457.54 & & & JKT & 9616.64 \\
\hline \multirow[t]{10}{*}{ HD 12953} & $\mathrm{H} \alpha$ & INT & $7431.62,7433.65$ & & $\mathrm{MgII}+\mathrm{HeI}$ & $\mathrm{CA}$ & 7457.58 \\
\hline & & $\mathrm{CA}$ & 7455.52 & & $\mathrm{H} \gamma+\mathrm{H} \delta$ & JKT & 9621.60 \\
\hline & & JKT & $9614.62,9615.59$ & \multirow[t]{7}{*}{ HD 15316} & $\mathrm{H} \alpha$ & INT & $7432.59,7434.57$ \\
\hline & \multirow[t]{2}{*}{ CaII } & INT & 7432.66 & & & $\mathrm{CA}$ & 7458.59 \\
\hline & & $\mathrm{CA}$ & $7452.55,7454.52$ & & & JKT & $9614.67,9615.64$ \\
\hline & \multirow[t]{2}{*}{$\mathrm{NaI}+\mathrm{HeI}$} & INT & 7434.64 & & $\mathrm{NaI}+\mathrm{HeI}$ & INT & 7434.69 \\
\hline & & $\mathrm{CA}$ & 7460.71 & & $\mathrm{H} \beta$ & $\mathrm{CA}$ & 7456.58 \\
\hline & $\mathrm{MgII}+\mathrm{HeI}$ & INT & 7434.70 & & & JKT & 9616.66 \\
\hline & \multirow[t]{2}{*}{$\mathrm{H} \beta$} & $\mathrm{CA}$ & 7456.52 & & $\mathrm{MgII}+\mathrm{HeI}$ & $\mathrm{CA}$ & 7457.60 \\
\hline & & JKT & 9616.58 & \multirow[t]{7}{*}{ HD 16778} & $\mathrm{H} \alpha$ & INT & $7432.60,7434.58$ \\
\hline \multirow[t]{9}{*}{ HD 13476} & \multirow[t]{3}{*}{$\mathrm{H} \alpha$} & INT & $7431.64,7433.66$ & & & JKT & $9614.68,9615.65$ \\
\hline & & $\mathrm{CA}$ & 7458.54 & & $\mathrm{NaI}+\mathrm{HeI}$ & INT & 7434.61 \\
\hline & & JKT & $9614.63,9615.60$ & & & JKT & 9621.73 \\
\hline & \multirow[t]{2}{*}{$\mathrm{NaI}+\mathrm{HeI}$} & INT & 7434.65 & & $\mathrm{H} \beta$ & $\mathrm{CA}$ & 7456.60 \\
\hline & & JKT & 9621.71 & & & JKT & 9616.67 \\
\hline & $\mathrm{H} \beta$ & $\mathrm{CA}$ & 7456.52 & & $\mathrm{MgII}+\mathrm{HeI}$ & $\mathrm{CA}$ & 7457.61 \\
\hline & & JKT & 9616.59 & HD 17378 & $\mathrm{H} \alpha$ & INT & $7431.66,7433.68$ \\
\hline & $\mathrm{MgII}+\mathrm{HeI}$ & $\mathrm{CA}$ & 7457.56 & & & $\mathrm{CA}$ & 7455.66 \\
\hline & $\mathrm{H} \gamma$ & JKT & 9621.58 & & & JKT & $9614.69,9615.68$ \\
\hline HD 13744 & $\mathrm{H} \alpha$ & INT & $7431.65,7433.66$ & & $\mathrm{NaI}+\mathrm{HeI}$ & INT & 7433.62 \\
\hline & & $\mathrm{CA}$ & 7458.55 & & CaII & INT & 7432.70 \\
\hline & & JKT & $9614.64,9615.60$ & & & $\mathrm{CA}$ & $7452.59,7454.60$ \\
\hline & $\mathrm{NaI}+\mathrm{HeI}$ & INT & 7434.66 & & $\mathrm{H} \beta$ & $\mathrm{CA}$ & 7456.64 \\
\hline & $\mathrm{H} \beta$ & $\mathrm{CA}$ & 7456.53 & & & JKT & 9616.70 \\
\hline & & JKT & 9616.60 & & $\mathrm{MgII}+\mathrm{HeI}$ & INT & 7434.74 \\
\hline & $\mathrm{MgII}+\mathrm{HeI}$ & $\mathrm{CA}$ & 7457.57 & & $\mathrm{H} \gamma+\mathrm{H} \delta$ & JKT & 9621.62 \\
\hline
\end{tabular}

Note: $\quad$ INT $=$ Isaac Newton Telescope + IDS;

$\mathrm{CA}=2.2 \mathrm{~m}$ Telescope, Calar Alto + Coudé;

$\mathrm{JKT}=$ Jacobus Kapteyn Telescope + RBS. 
Table 4. continued

\begin{tabular}{|c|c|c|c|c|c|c|c|}
\hline STAR & Sp. Range & Tel. & JD-2440000. & STAR & Sp. Range & Tel. & JD-2440000. \\
\hline \multirow[t]{10}{*}{ HD 20041} & \multirow[t]{3}{*}{$\mathrm{H} \alpha$} & INT & $7432.63,7434.59$ & \multirow[t]{7}{*}{ HD 210221} & $\mathrm{H} \alpha$ & INT & $7432.37,7434.38$ \\
\hline & & $\mathrm{CA}$ & 7455.65 & & & $\mathrm{CA}$ & 7458.34 \\
\hline & & JKT & $9614.69,9615.68$ & & & JKT & 9614.45 \\
\hline & \multirow[t]{2}{*}{$\mathrm{NaI}+\mathrm{HeI}$} & INT & $7433.76,7434.60$ & & $\mathrm{NaI}+\mathrm{HeI}$ & INT & 7433.52 \\
\hline & & JKT & 9621.73 & & $\mathrm{CaII}$ & $\mathrm{CA}$ & 7452.39 \\
\hline & $\mathrm{CaII}$ & $\mathrm{CA}$ & 7457.68 & & $\mathrm{H} \beta$ & $\mathrm{CA}$ & 7456.36 \\
\hline & \multirow[t]{2}{*}{$\mathrm{H} \beta$} & $\mathrm{CA}$ & 7456.65 & & & JKT & 9616.47 \\
\hline & & JKT & 9616.70 & \multirow[t]{8}{*}{ HD 211971} & $\mathrm{H} \alpha$ & INT & $7432.38,7434.38$ \\
\hline & $\mathrm{MgII}+\mathrm{HeI}$ & $\mathrm{CA}$ & 7457.66 & & $\mathrm{NaI}+\mathrm{HeI}$ & INT & 7433.53 \\
\hline & $\mathrm{H} \gamma+\mathrm{H} \delta$ & JKT & 9621.64 & & & JKT & 9621.40 \\
\hline \multirow[t]{10}{*}{ HD 21389} & \multirow[t]{3}{*}{$\mathrm{H} \alpha$} & INT & $7431.67,7433.70$ & & CaII & $\mathrm{CA}$ & 7455.39 \\
\hline & & $\mathrm{CA}$ & 7455.64 & & $\mathrm{H} \beta$ & $\mathrm{CA}$ & 7456.37 \\
\hline & & JKT & $9614.70,9615.69$ & & & JKT & 9616.48 \\
\hline & \multirow[t]{2}{*}{$\mathrm{NaI}+\mathrm{HeI}$} & INT & 7433.73 & & $\mathrm{MgII}+\mathrm{HeI}$ & INT & 7433.37 \\
\hline & & $\mathrm{JKT}$ & 9621.74 & & $\mathrm{H} \gamma+\mathrm{H} \delta$ & JKT & 9618.51 \\
\hline & \multirow[t]{2}{*}{ CaII } & INT & 7432.72 & \multirow[t]{8}{*}{ HD 212593} & $\mathrm{H} \alpha$ & INT & 7432.38 \\
\hline & & $\mathrm{CA}$ & 7452.64 & & & $\mathrm{CA}$ & 7458.35 \\
\hline & \multirow[t]{2}{*}{$\mathrm{H} \beta$} & $\mathrm{CA}$ & 7456.66 & & & JKT & 9614.48 \\
\hline & & JKT & 9616.72 & & $\mathrm{NaI}+\mathrm{HeI}$ & INT & 7433.53 \\
\hline & $\mathrm{MgII}+\mathrm{HeI}$ & INT & 7432.77 & & CaII & $\mathrm{CA}$ & 7454.38 \\
\hline \multirow[t]{8}{*}{ HD 46300} & \multirow[t]{2}{*}{$\mathrm{H} \alpha$} & INT & $7431.68,7433.71$ & & $\mathrm{H} \beta$ & $\mathrm{CA}$ & 7456.38 \\
\hline & & $\mathrm{CA}$ & 7455.69 & & & JKT & 9616.49 \\
\hline & $\mathrm{NaI}+\mathrm{HeI}$ & INT & 7433.72 & & $\mathrm{MgII}+\mathrm{HeI}$ & INT & 7433.38 \\
\hline & \multirow[t]{2}{*}{ CaII } & INT & 7432.73 & \multirow[t]{10}{*}{ HD 213470} & $\mathrm{H} \alpha$ & INT & $7432.39,7434.40$ \\
\hline & & $\mathrm{CA}$ & 7452.72 & & & $\mathrm{CA}$ & 7458.36 \\
\hline & $\mathrm{H} \beta$ & $\mathrm{CA}$ & 7456.66 & & & JKT & $9614.50,9615.48$ \\
\hline & $\mathrm{MgII}+\mathrm{HeI}$ & INT & 7432.76 & & $\mathrm{NaI}+\mathrm{HeI}$ & INT & 7433.54 \\
\hline & $\mathrm{H} \gamma+\mathrm{H} \delta$ & JKT & 9617.74 & & & JKT & 9621.40 \\
\hline \multirow[t]{3}{*}{ HD 187982} & $\mathrm{H} \alpha$ & JKT & $9614.44,9614.51$ & & CaII & $\mathrm{CA}$ & 7457.32 \\
\hline & $\mathrm{NaI}+\mathrm{HeI}$ & JKT & 9621.36 & & $\mathrm{H} \beta$ & $\mathrm{CA}$ & 7456.39 \\
\hline & $\mathrm{H} \beta$ & JKT & 9616.41 & & & JKT & 9616.50 \\
\hline HD 197345 & $\mathrm{H} \alpha$ & INT & $7432.33,7434.35$ & & $\mathrm{MgII}+\mathrm{HeI}$ & INT & 7433.39 \\
\hline & & JKT & 9614.36 & & $\mathrm{H} \gamma+\mathrm{H} \delta$ & JKT & 9621.45 \\
\hline & $\mathrm{NaI}+\mathrm{HeI}$ & INT & 7433.50 & $\mathrm{BD}+602542$ & $\mathrm{H} \alpha$ & INT & $7432.40,7434.41$ \\
\hline & & JKT & 9621.37 & & & JKT & 9614.57 \\
\hline & CaII & INT & 7433.46 & & $\mathrm{NaI}+\mathrm{HeI}$ & INT & 7433.54 \\
\hline & & $\mathrm{CA}$ & $7452.35,7455.36$ & & CaII & $\mathrm{CA}$ & 7457.34 \\
\hline & $\mathrm{H} \beta$ & $\mathrm{CA}$ & 7456.30 & & $\mathrm{H} \beta$ & $\mathrm{CA}$ & 7456.40 \\
\hline & & JKT & 9616.39 & & $\mathrm{MgII}+\mathrm{HeI}$ & $\mathrm{CA}$ & 7457.37 \\
\hline & $\mathrm{MgII}+\mathrm{HeI}$ & INT & 7433.34 & HD 223385 & $\mathrm{H} \alpha$ & INT & 7432.44 \\
\hline HD 207260 & $\mathrm{H} \alpha$ & INT & $7432.33,7434.35$ & & & $\mathrm{CA}$ & 7458.38 \\
\hline & & $\mathrm{CA}$ & 7458.33 & & $\mathrm{NaI}+\mathrm{HeI}$ & INT & 7433.56 \\
\hline & & JKT & $9614.36,9615.42$ & & & $\mathrm{CA}$ & 7456.48 \\
\hline & $\mathrm{NaI}+\mathrm{HeI}$ & INT & 7433.50 & & & JKT & 9621.42 \\
\hline & & JKT & 9621.38 & & CaII & INT & 7433.45 \\
\hline & CaII & INT & 7433.44 & & & $\mathrm{CA}$ & 7454.40 \\
\hline & & $\mathrm{CA}$ & 7452.36 & & $\mathrm{H} \beta$ & $\mathrm{CA}$ & 7456.42 \\
\hline & $\mathrm{H} \beta$ & $\mathrm{CA}$ & 7456.34 & & $\mathrm{MgII}+\mathrm{HeI}$ & $\mathrm{CA}$ & 7457.39 \\
\hline & & JKT & 9616.42 & & $\mathrm{H} \gamma+\mathrm{H} \delta$ & JKT & 9621.51 \\
\hline & $\mathrm{MgII}+\mathrm{HeI}$ & INT & 7433.35 & & & & \\
\hline & $\mathrm{H} \gamma+\mathrm{H} \delta$ & JKT & 9618.47 & & & & \\
\hline HD 207673 & $\mathrm{H} \alpha$ & JKT & $9614.43,9614.52$ & & & & \\
\hline & $\mathrm{NaI}+\mathrm{HeI}$ & JKT & 9621.39 & & & & \\
\hline & $\mathrm{H} \beta$ & JKT & 9616.43 & & & & \\
\hline & $\mathrm{H} \gamma+\mathrm{H} \delta$ & JKT & 9618.47 & & & & \\
\hline
\end{tabular}


Table 4. continued

\begin{tabular}{|c|c|c|c|c|c|c|c|}
\hline STAR & Sp. Range & Tel. & JD-2440000. & STAR & Sp. Range & Tel. & JD-2440000. \\
\hline HD 209900 & $\begin{array}{l}\mathrm{H} \alpha \\
\mathrm{NaI}+\mathrm{HeI} \\
\mathrm{CaII} \\
\mathrm{H} \beta \\
\mathrm{MgII}+\mathrm{HeI}\end{array}$ & $\begin{array}{l}\text { INT } \\
\text { JKT } \\
\text { INT } \\
\text { CA } \\
\text { CA } \\
\text { JKT } \\
\text { INT }\end{array}$ & $\begin{array}{l}7432.34,7434.35 \\
9614.41 \\
7433.51 \\
7457.29 \\
7458.29 \\
9616.44 \\
7433.40\end{array}$ & HD 223960 & $\begin{array}{l}\mathrm{H} \alpha \\
\mathrm{NaI}+\mathrm{HeI} \\
\mathrm{CaII} \\
\mathrm{H} \beta \\
\mathrm{MgII}+\mathrm{HeI} \\
\mathrm{H} \gamma+\mathrm{H} \delta\end{array}$ & $\begin{array}{l}\text { INT } \\
\text { CA } \\
\text { JKT } \\
\text { INT } \\
\text { JKT } \\
\text { INT } \\
\text { CA } \\
\text { CA } \\
\text { JKT } \\
\text { INT } \\
\text { JKT }\end{array}$ & $\begin{array}{l}7432.44,7434.44 \\
7458.44 \\
9614.65,9615.53 \\
7433.57 \\
9621.42 \\
7433.46 \\
7454.43 \\
7448.31 \\
9616.54 \\
7431.52 \\
9621.47\end{array}$ \\
\hline
\end{tabular}

Spectrograph (Baudrand \& Böhm 1992) coupled to the $2 \mathrm{~m}$ Bernard Lyot Telescope (TBL) by means of a double optical fiber of $50 \mu \mathrm{m}$ core diameter (due to the mechanical separation of the spectrograph from the telescope, excellent stability is guaranteed during the night). The MUSICOS spectrograph works in cross-dispersion mode allowing the observation of whole visible range (from $380 \mathrm{~nm}$ to $880 \mathrm{~nm}$ ) in two exposures with a resolving power around 38000 . Six stars of our sample were observed with this instrument.

The last campaign was carried out in September 1994 with the Jacobus Kapteyn Telescope of the Roque de los Muchachos Observatory in La Palma. We used the Richardson Brealey Spectrograph (RBS) with a TEK CCD which has $24 \mu \mathrm{m}$ pixels arranged in a $1024 \times 1024$ array. In this campaign we paid special attention to the $\mathrm{H} \gamma$ and $\mathrm{H} \delta$ lines which were observed simultaneously with a resolving power around 3700 .

The spectra of the two southern stars (HD 59612 and HD 102878) were kindly provided to us by Andreas Kaufer. These spectra were taken in La Silla with the Heidelberg Extended Range Optical Spectrograph (HEROS) at the ESO $50 \mathrm{~cm}$ telescope. HEROS is a portable fibre-linked two-channel echelle spectrograph which covers from $345 \mathrm{~nm}$ to $560 \mathrm{~nm}$ and from $580 \mathrm{~nm}$ to $865 \mathrm{~nm}$ in one exposure. The resolving power is around 20000 over the complete wavelength range and, as with MUSICOS, stability is guaranteed by the separation from the telescope.

\subsubsection{Reduction}

The spectra obtained at La Palma and Calar Alto have been processed using standard astronomical data reduction packages (IHAP (Middelburg 1981), MIDAS ${ }^{1}$ and

\footnotetext{
1 Munich Image Data Analysis System, European Southern Observatory.
}

$\left.\mathrm{IRAF}^{2}\right)$. In all cases the spectra have been extracted from the CCD frame after dark noise correction and flatfielding. At this stage, each spectrum was rebinned into a wavelength scale by using a polynomial fit to the positions provided by the comparison lamps (ThAr, ThNe or $\mathrm{CuNe}$. A calibration spectrum was obtained immediately after the stellar spectrum, without any change in the spectrograph configuration. The long-term accuracy achieved for the wavelength calibration is of the order of $1 \mathrm{~km} \mathrm{~s}^{-1}$.

In the final step the resulting wavelength-calibrated spectrum was rebinned to heliocentric velocities and the continuum was normalized to unity by fitting a low-order polynomial and dividing the spectrum by this function.

The MUSICOS spectra were semi-automatically reduced with the dedicated software MUSBIC. A complete description of this procedure can be found in Baudrand \& Böhm (1992). Briefly, as the acquisition, the reduction is divided into two spectral domains: the red $(550-890 \mathrm{~nm})$ and the blue $(390-550 \mathrm{~nm})$. Both domains are precisely defined with regard to the order positions. The first step carried out by the program is to determine the exact position of the orders. The procedure is performed on the stellar, flatfield and calibration spectra. Then the program extracts each order of these spectra. The half-widths of the nearly Gaussian order profiles (perpendicular to the dispersion) vary between 2.5 and $3.5 \mathrm{pxl}$ for the blue and for the red domain respectively. Therefore the extraction width is usually $7 \mathrm{pxl}$ for the blue domain and $9 \mathrm{pxl}$ for the red, to contain most of the signal. The program integrates the extracted signal above the baseline defined by the mean value of the signal at the adjacent interorder positions. Two data tables contain wavelengths and pixel positions of all significant emission lines for each order of a thorium reference spectrum. Starting from guessed positions read in the tables, the program finds the exact positions and automatically deduces for each order the

\footnotetext{
${ }^{2}$ Image Reduction and Analysis Facility, National Optical Astronomy Observatories.
} 
Table 5. IUE observations

\begin{tabular}{|c|c|c|c|}
\hline Star & JD-2400000. & LWP & Exp. T (m) \\
\hline HD 2928 & 50031.973 & 31681 & 300 \\
\hline HD 3940 & 50009.176 & 31605 & 105 \\
\hline HD 5776 & 50013.217 & 31615 & 200 \\
\hline \multirow[t]{5}{*}{ HD 12953} & 46698.362 & 9167 & 037 \\
\hline & 46705.213 & 9224 & 037 \\
\hline & 46714.169 & 9290 & 037 \\
\hline & 46722.172 & 9350 & 037 \\
\hline & 46729.196 & 9407 & 037 \\
\hline HD 13476 & 49664.225 & 29471 & 083 \\
\hline HD 13744 & 50005.497 & 31590 & 150 \\
\hline \multirow[t]{3}{*}{ HD 14433} & 46698.273 & 9166 & 072 \\
\hline & 46705.272 & 9225 & 042 \\
\hline & 46714.224 & 9291 & 035 \\
\hline HD 14535 & 49664.114 & 29470 & 120 \\
\hline HD 15316 & 49664.031 & 29469 & 075 \\
\hline HD 16778 & 50007.065 & 31602 & 170 \\
\hline HD 17378 & 46698.421 & 9168 & 040 \\
\hline HD 20041 & 49663.985 & 29468 & 020 \\
\hline \multirow[t]{5}{*}{ HD 21389} & 46698.231 & 9165 & 008 \\
\hline & 46705.331 & 9226 & 008 \\
\hline & 46714.278 & 9292 & 008 \\
\hline & 46722.133 & 9349 & 010 \\
\hline & 46729.148 & 9406 & 010 \\
\hline \multirow[t]{4}{*}{ HD 46300} & 46698.143 & 9163 & 005 \\
\hline & 46714.114 & 9289 & 004 \\
\hline & 46722.076 & 9348 & 004 \\
\hline & 46729.086 & 9405 & 004 \\
\hline \multirow[t]{2}{*}{ HD 59612} & 46698.185 & 9164 & 030 \\
\hline & 48596.899 & 21952 & 020 \\
\hline \multirow[t]{6}{*}{ HD 87737} & 48577.184 & 21753 & 005 \\
\hline & 48583.044 & 21808 & 001 \\
\hline & 48588.976 & 21871 & 001 \\
\hline & 48589.272 & 21876 & 001 \\
\hline & 48596.995 & 21954 & 001 \\
\hline & 48612.076 & 22044 & 001 \\
\hline HD 100198 & 49480.707 & 28096 & 040 \\
\hline HD 100826 & 49480.667 & 28095 & 023 \\
\hline HD 102878 & 49480.762 & 28097 & 023 \\
\hline HD 103516 & 49480.549 & 28093 & 030 \\
\hline HD 104035 & 49480.513 & 28092 & 015 \\
\hline HD 104111 & 49480.596 & 28094 & 060 \\
\hline HD 161912 & 49481.474 & 28091 & 005 \\
\hline HD 207673 & 50032.235 & 31682 & 050 \\
\hline HD 210221 & 48612.188 & 22046 & 017 \\
\hline HD 211971 & 48583.083 & 21809 & 045 \\
\hline \multirow[t]{2}{*}{ HD 212593} & 48589.235 & 21875 & 005 \\
\hline & 48597.035 & 21955 & 004 \\
\hline HD 213470 & 49700.159 & 29702 & 057 \\
\hline
\end{tabular}

Table 6. Interstellar components used for wavelength calibration

\begin{tabular}{ccc}
\hline Ion & Mult. & $\lambda(\AA)$ \\
\hline Fe II & 3 & 2343.495 \\
Fe II & 2 & 2366.864 \\
& & 2373.733 \\
& & 2382.034 \\
Fe II & 1 & 2585.876 \\
& & 2599.395 \\
Mn II & 1 & 2576.107 \\
& & 2593.731 \\
& & 2605.697 \\
Mg II & 1 & 2795.523 \\
& 1 & 2802.698 \\
Mg I & 1 & 2852.120 \\
\hline
\end{tabular}

coefficients of the 3rd order polynomial giving the wavelength calibration.

\section{2. $U V$ data}

\subsubsection{Observations}

The stars observed with the IUE satellite are all the A-supergiants in the 1986 IUE Archive, studied before by Talavera \& Gómez de Castro (1987), as well as the new set observed by us in campaigns during 1986, 1991, 1994 and 1995. The new spectra were taken using the prime camera of the long-wavelength IUE spectrograph (LWP) in high-resolution mode. The spectral range observed with this configuration is from $1900 \AA$ to $3200 \AA$ with a resolution of $\sim 0.2 \AA$; the most prominent indicators of wind in A-supergiants, Mg II and Fe II lines, are observed in this range.

The IUE observations carried out by us are summarized in Table 5. For each star the date of observation, the image number and the exposure time are provided.

\subsubsection{Reduction}

All IUE data have been processed at VILSPA using the IUE Spectral Image Processing System (IUESIPS). IUESIPS produces data as free as possible from instrumental effects. These include geometric distortion correction, photometric nonlinearity correction, spectral order extraction and wavelength and flux calibration.

The standard IUE data reduction has an uncertainty in the zero of the wavelength scale which can amount up to $0.5 \AA$. To correct for this we have measured the observed wavelength of some selected interstellar lines listed in Table 6 and compared with their laboratory wavelength. This method cannot be used in some stars for which the lines selected are not clearly interstellar (lines wider than the IUE instrumental profile). In such a case we compared 
Table 7. Visible lines selected for this atlas

\begin{tabular}{|c|c|c|c|c|c|c|c|c|}
\hline Ion & $\lambda(\AA)$ & $\log g f$ & $E_{i}\left(\mathrm{~cm}^{-1}\right)$ & $j_{i}$ & Config $_{i}$ & $E_{\mathrm{f}}\left(\mathrm{cm}^{-1}\right)$ & $j_{\mathrm{f}}$ & Config $_{f}$ \\
\hline $\mathrm{H} \alpha$ & 6562.80 & 0.7098 & 82259 & $(1 / 2,3 / 2)$ & $2 \mathrm{p}^{2} \mathrm{P}^{0}$ & 97492 & $(3 / 2,5 / 2)$ & $3 d^{2} D$ \\
\hline $\mathrm{H} \beta$ & 4861.32 & -0.0202 & 82259 & $(1 / 2,3 / 2)$ & $2 \mathrm{p}^{2} \mathrm{P}^{0}$ & 102824 & $(3 / 2,5 / 2)$ & $4 d^{2} \mathrm{D}$ \\
\hline $\mathrm{H} \gamma$ & 4340.46 & -0.4469 & 82259 & $(1 / 2,3 / 2)$ & $2 \mathrm{p}^{2} \mathrm{P}^{0}$ & 105292 & $(3 / 2,5 / 2)$ & $5 \mathrm{~d}^{2} \mathrm{D}$ \\
\hline $\mathrm{H} \delta$ & 4101.73 & -0.7527 & 82259 & $(1 / 2,3 / 2)$ & $2 \mathrm{p}^{2} \mathrm{P}^{0}$ & 106632 & $(3 / 2,5 / 2)$ & $6 \mathrm{~d}^{2} \mathrm{D}$ \\
\hline $\mathrm{H} \epsilon$ & 3970.07 & -0.9929 & 82259 & $(1 / 2,3 / 2)$ & $2 \mathrm{p}^{2} \mathrm{P}^{0}$ & 107440 & $(3 / 2,5 / 2)$ & $7 \mathrm{~d}^{2} \mathrm{D}$ \\
\hline \multirow[t]{2}{*}{ He I } & 5875.7 & 0.739 & 169087 & $(2,1,0)$ & $2 \mathrm{p}^{3} \mathrm{P}^{0}$ & 186102 & $(3,2,1)$ & $3 d^{3} \mathrm{D}$ \\
\hline & 4471.5 & 0.052 & 169087 & $(2,1,0)$ & $2 \mathrm{p}^{3} \mathrm{P}^{0}$ & 191445 & $(3,2,1)$ & $4 d^{3} \mathrm{D}$ \\
\hline \multirow[t]{2}{*}{$\mathrm{Na} \mathrm{I}$} & 5895.92 & -0.184 & 0 & $1 / 2$ & $3 \mathrm{~s}{ }^{2} \mathrm{~S}$ & 16956 & $1 / 2$ & $3 p^{2} \mathrm{P}^{0}$ \\
\hline & 5889.95 & 0.117 & 0 & $1 / 2$ & $3 \mathrm{~s}^{2} \mathrm{~S}$ & 16968 & $3 / 2$ & $3 \mathrm{p}^{2} \mathrm{P}^{0}$ \\
\hline \multirow[t]{2}{*}{ Ca II } & 3968.47 & -0.162 & 0 & $1 / 2$ & $4 \mathrm{~s}^{2} \mathrm{~S}$ & 25192 & $1 / 2$ & $4 \mathrm{p}^{2} \mathrm{P}^{0}$ \\
\hline & 3933.66 & 0.140 & 0 & $1 / 2$ & $4 s^{2} \mathrm{~S}$ & 25414 & $3 / 2$ & $4 \mathrm{p}^{2} \mathrm{P}^{0}$ \\
\hline Mg II & 4481.2 & 0.978 & 71491 & $(5 / 2,3 / 2)$ & $3 \mathrm{~d}^{2} \mathrm{D}$ & 93800 & $(5 / 2,7 / 2)$ & $4 \mathrm{f}^{2} \mathrm{~F}^{0}$ \\
\hline
\end{tabular}

the observed spectrum with that of HD 46300 which shows several narrow lines, and henceforth can be used as a reliable template.

Finally, the lines have been normalized to a nearby continuum; we have selected the same continuum windows as Talavera \& Gómez de Castro (1987).

\section{The spectral atlas}

The lines studied in this work have been selected because:

1. Either they are good tracers of winds and mass outflow. For instance not all the UV lines obtained in the $1900-3200 \AA$ range with IUE are represented. We have selected a sub-sample based on the previous work of Talavera \& Gómez de Castro (1987).

2. Or they are useful spectroscopic indicators for the determination of stellar parameters: effective temperature, gravity and rotational velocity.

The selected lines are listed in Table 7 (visible) and Table 8 (ultraviolet) together with their basic atomic parameters. For the ultraviolet lines, the atomic data come from the semi-empirical calculations of Kurucz \& Peytremann (1975).

The atlas, which is accesible from the CDS via ftp, is presented in a comprehensible way by means of two different kind of plots. The spectral atlas of stars with visible spectra only is presented with three stars per page. The line profiles of each star are represented in 7 different panels. These plots are designated collectively as Fig. 1 . The spectral atlas of stars with both visible and IUE spectra or with IUE spectra only is presented with one star per page. All the line profiles corresponding to the same star are displayed in 12 different panels within the same page. These plots are designated collectively as Fig. 2 . We provide the $\mathrm{HD} / \mathrm{BD}$ number, the spectral type and the absolute visual magnitude for each star.

The profiles (normalized to the nearby continuum) are plotted versus wavelength (in $\AA$ ). The visible lines are displayed in the first seven panels corresponding to: the lines of H I Balmer series, He I and Mg II and the doublet lines of Ca II and Na I. The ultraviolet lines are shown in bottom panels: Mg II (uv1) and Fe II (uv1, uv2, uv3, uv62, uv63, uv161). The laboratory wavelengths of the lines are marked by a dashed vertical line. Empty panels indicate that there are no observations at this wavelength range for a given star.

The flux scale varies from source to source to better display the observed profiles. We have selected for each star the best quality spectra obtained (best $\mathrm{S} / \mathrm{N}$ ratio and spectral resolution) of all these available from the different campaigns. The IUE spectra are often very noisy, especially at the shortest wavelength. Where that was the case we smoothed the spectrum with a boxcar of two, three or five points in order to show a decent profile.

We have observed most of the stars several times in various spectral ranges to study their variability. Variations have been detected in $\mathrm{H} \alpha, \mathrm{Mg}$ II (uv1) and Fe II (uv1, uv62, uv63). No evidence of variability has been detected in the other lines. We have represented in Fig. 3 a summary of this study. Figure 3 is presented in the form of a single plot for each star containing two or more spectra. The spectra are labeled with the date of observation and with the $\mathrm{HD} / \mathrm{BD}$ number of the star. All the $\mathrm{H} \alpha$ profiles are displayed for each variable Asupergiant. We have also selected some few representative examples of variations in the UV range. As in Fig. 1 the laboratory wavelength of the lines is marked.

\section{Results}

Our findings can be summarized as follows:

H I.- The $\mathrm{H} \alpha$ line is shown to be the most sensitive visible indicator of stellar winds in A-type supergiants. The profiles vary from pure symmetric absorption in the less luminous stars to variable emission profiles in some sources. As noted by Rosendhal (1973) the influence of luminosity upon the shape of $\mathrm{H} \alpha$ follows a clear trend: as 
Table 8. Ultraviolet lines selected for this atlas

\begin{tabular}{|c|c|c|c|c|c|c|c|c|}
\hline Ion & $\lambda(\AA)$ & $\log g f$ & $E_{i}\left(\mathrm{~cm}^{-1}\right)$ & $j_{i}$ & Config $_{i}$ & $E_{\mathrm{f}}\left(\mathrm{cm}^{-1}\right)$ & $j_{\mathrm{f}}$ & Config $_{f}$ \\
\hline \multirow[t]{2}{*}{ Mg II (1) } & 2802.70 & -0.203 & 0.000 & $1 / 2$ & $3 \mathrm{~s}^{2} \mathrm{~S}$ & 35669.310 & $1 / 2$ & $3 \mathrm{p}^{2} \mathrm{P}^{0}$ \\
\hline & 2795.53 & 0.098 & 0.000 & $1 / 2$ & $3 \mathrm{~s}^{2} \mathrm{~S}$ & 35760.880 & $3 / 2$ & $3 \mathrm{p}^{2} \mathrm{P}^{0}$ \\
\hline \multirow[t]{10}{*}{ Fe II (63) } & 2772.719 & -1.533 & 8391.938 & $5 / 2$ & $\mathrm{a}^{4} \mathrm{D}$ & 44446.878 & $7 / 2$ & $\mathrm{z}^{4} \mathrm{D}^{0}$ \\
\hline & 2768.940 & -0.971 & 8680.454 & $3 / 2$ & $a^{4} D$ & 44784.761 & $5 / 2$ & $\mathrm{z}^{4} \mathrm{D}^{0}$ \\
\hline & 2761.813 & -0.898 & 8846.768 & $1 / 2$ & $a^{4} D$ & 45044.168 & $3 / 2$ & $\mathrm{z}^{4} \mathrm{D}^{0}$ \\
\hline & 2749.482 & -0.581 & 8846.768 & $1 / 2$ & $a^{4} \mathrm{D}$ & 45206.450 & $1 / 2$ & $\mathrm{z}^{4} \mathrm{D}^{0}$ \\
\hline & 2749.182 & -0.281 & 8680.454 & $3 / 2$ & $a^{4} D$ & 45044.168 & $3 / 2$ & $\mathrm{z}^{4} \mathrm{D}^{0}$ \\
\hline & 2746.978 & 0.055 & 8391.938 & $5 / 2$ & $\mathrm{a}^{4} \mathrm{D}$ & 44784.761 & $5 / 2$ & $\mathrm{z}^{4} \mathrm{D}^{0}$ \\
\hline & 2739.545 & 0.331 & 7955.299 & $7 / 2$ & $a^{4} D$ & 44446.878 & $7 / 2$ & $\mathrm{z}^{4} \mathrm{D}^{0}$ \\
\hline & 2736.968 & -0.545 & 8680.454 & $3 / 2$ & $a^{4} D$ & 45206.450 & $1 / 2$ & $\mathrm{z}^{4} \mathrm{D}^{0}$ \\
\hline & 2727.538 & -0.349 & 8391.938 & $5 / 2$ & $a^{4} D$ & 45044.168 & $3 / 2$ & $\mathrm{z}^{4} \mathrm{D}^{0}$ \\
\hline & 2714.414 & -0.398 & 7955.299 & $7 / 2$ & $a^{4} \mathrm{D}$ & 44784.761 & $5 / 2$ & $\mathrm{z}^{4} \mathrm{D}^{0}$ \\
\hline \multirow[t]{9}{*}{ Fe II (62) } & 2755.733 & 0.425 & 7955.299 & $7 / 2$ & $a^{4} D$ & 44232.512 & $9 / 2$ & $\mathrm{z}^{4} \mathrm{~F}^{0}$ \\
\hline & 2749.324 & 0.323 & 8391.938 & $5 / 2$ & $a^{4} D$ & 44753.799 & $7 / 2$ & $\mathrm{z}^{4} \mathrm{~F}^{0}$ \\
\hline & 2746.487 & 0.163 & 8680.454 & $3 / 2$ & $a^{4} D$ & 45079.879 & $5 / 2$ & $\mathrm{z}^{4} \mathrm{~F}^{0}$ \\
\hline & 2743.196 & -0.050 & 8846.768 & $1 / 2$ & $a^{4} \mathrm{D}$ & 45289.801 & $3 / 2$ & $\mathrm{z}^{4} \mathrm{~F}^{0}$ \\
\hline & 2730.735 & -0.712 & 8680.454 & $3 / 2$ & $a^{4} \mathrm{D}$ & 45289.801 & $3 / 2$ & $\mathrm{z}^{4} \mathrm{~F}^{0}$ \\
\hline & 2724.879 & -0.800 & 8391.938 & $5 / 2$ & $a^{4} D$ & 45079.879 & $5 / 2$ & $\mathrm{z}^{4} \mathrm{~F}^{0}$ \\
\hline & 2716.683 & -1.484 & 7955.299 & $7 / 2$ & $a^{4} D$ & 44753.799 & $7 / 2$ & $\mathrm{z}^{4} \mathrm{~F}^{0}$ \\
\hline & 2709.373 & -2.858 & 8391.938 & $5 / 2$ & $a^{4} D$ & 45289.801 & $3 / 2$ & $\mathrm{z}^{4} \mathrm{~F}^{0}$ \\
\hline & 2692.826 & -3.239 & 7955.299 & $7 / 2$ & $a^{4} D$ & 45079.879 & $5 / 2$ & $\mathrm{z}^{4} \mathrm{~F}^{0}$ \\
\hline \multirow[t]{13}{*}{ Fe II (1) } & 2631.321 & -0.274 & 667.683 & $5 / 2$ & $a^{6} \mathrm{D}$ & 38660.043 & $7 / 2$ & $\mathrm{z}^{6} \mathrm{D}^{0}$ \\
\hline & 2631.045 & -0.271 & 862.613 & $3 / 2$ & $a^{6} \mathrm{D}$ & 38858.958 & $5 / 2$ & $\mathrm{z}^{6} \mathrm{D}^{0}$ \\
\hline & 2628.291 & -0.425 & 977.053 & $1 / 2$ & $a^{6} \mathrm{D}$ & 39013.206 & $3 / 2$ & $\mathrm{z}^{6} \mathrm{D}^{0}$ \\
\hline & 2625.664 & -0.435 & 384.790 & $7 / 2$ & $a^{6} \mathrm{D}$ & 38458.981 & $9 / 2$ & $\mathrm{z}^{6} \mathrm{D}^{0}$ \\
\hline & 2621.669 & -0.930 & 977.053 & $1 / 2$ & $a^{6} \mathrm{D}$ & 39109.307 & $1 / 2$ & $\mathrm{z}^{6} \mathrm{D}^{0}$ \\
\hline & 2620.408 & -1.801 & 862.613 & $3 / 2$ & $a^{6} \mathrm{D}$ & 39013.206 & $3 / 2$ & $\mathrm{z}^{6} \mathrm{D}^{0}$ \\
\hline & 2617.618 & -0.508 & 667.683 & $5 / 2$ & $a^{6} \mathrm{D}$ & 38858.958 & $5 / 2$ & $\mathrm{z}^{6} \mathrm{D}^{0}$ \\
\hline & 2613.820 & -0.322 & 862.613 & $3 / 2$ & $a^{6} \mathrm{D}$ & 39109.307 & $1 / 2$ & $\mathrm{z}^{6} \mathrm{D}^{0}$ \\
\hline & 2611.873 & 0.032 & 384.790 & $7 / 2$ & $a^{6} \mathrm{D}$ & 38660.043 & $7 / 2$ & $\mathrm{z}^{6} \mathrm{D}^{0}$ \\
\hline & 2607.086 & -0.099 & 667.683 & $5 / 2$ & $a^{6} \mathrm{D}$ & 39013.206 & $3 / 2$ & $\mathrm{z}^{6} \mathrm{D}^{0}$ \\
\hline & 2599.395 & 0.417 & 0.000 & $9 / 2$ & $a^{6} \mathrm{D}$ & 38458.981 & $9 / 2$ & $\mathrm{z}^{6} \mathrm{D}^{0}$ \\
\hline & 2598.369 & -0.029 & 384.790 & $7 / 2$ & $a^{6} \mathrm{D}$ & 38858.958 & $5 / 2$ & $\mathrm{z}^{6} \mathrm{D}^{0}$ \\
\hline & 2585.876 & -0.116 & 0.000 & $9 / 2$ & $a^{6} \mathrm{D}$ & 38660.043 & $7 / 2$ & $\mathrm{z}^{6} \mathrm{D}^{0}$ \\
\hline Fe II (161) & 2498.897 & 0.365 & 21581.638 & $9 / 2$ & $\mathrm{a}^{4} \mathrm{H}$ & 61587.214 & $11 / 2$ & $\mathrm{z}^{4} \mathrm{I}^{0}$ \\
\hline \multirow[t]{14}{*}{ Fe II (2) } & 2413.308 & -0.397 & 977.053 & $1 / 2$ & $a^{6} \mathrm{D}$ & 42401.302 & $3 / 2$ & $\mathrm{z}^{6} \mathrm{~F}^{0}$ \\
\hline & 2411.062 & -0.327 & 977.053 & $1 / 2$ & $a^{6} \mathrm{D}$ & 42439.822 & $1 / 2$ & $\mathrm{z}^{6} \mathrm{~F}^{0}$ \\
\hline & 2410.521 & -0.033 & 862.613 & $3 / 2$ & $a^{6} \mathrm{D}$ & 42334.822 & $5 / 2$ & $\mathrm{z}^{6} \mathrm{~F}^{0}$ \\
\hline & 2406.660 & -0.175 & 862.613 & $3 / 2$ & $a^{6} \mathrm{D}$ & 42401.302 & $3 / 2$ & $\mathrm{z}^{6} \mathrm{~F}^{0}$ \\
\hline & 2404.882 & 0.201 & 667.683 & $5 / 2$ & $a^{6} \mathrm{D}$ & 42237.033 & $7 / 2$ & $\mathrm{z}^{6} \mathrm{~F}^{0}$ \\
\hline & 2404.430 & -0.936 & 862.613 & $3 / 2$ & $a^{6} \mathrm{D}$ & 42439.822 & $1 / 2$ & $\mathrm{z}^{6} \mathrm{~F}^{0}$ \\
\hline & 2399.242 & -0.107 & 667.683 & $5 / 2$ & $a^{6} \mathrm{D}$ & 42334.822 & $5 / 2$ & $\mathrm{z}^{6} \mathrm{~F}^{0}$ \\
\hline & 2395.627 & 0.413 & 384.790 & $7 / 2$ & $a^{6} \mathrm{D}$ & 42114.818 & $9 / 2$ & $\mathrm{z}^{6} \mathrm{~F}^{0}$ \\
\hline & 2395.416 & -0.992 & 667.683 & $5 / 2$ & $a^{6} \mathrm{D}$ & 42401.302 & $3 / 2$ & $\mathrm{z}^{6} \mathrm{~F}^{0}$ \\
\hline & 2388.629 & -0.131 & 384.790 & $7 / 2$ & $a^{6} \mathrm{D}$ & 42237.033 & $7 / 2$ & $\mathrm{z}^{6} \mathrm{~F}^{0}$ \\
\hline & 2383.060 & -1.337 & 384.790 & $7 / 2$ & $a^{6} \mathrm{D}$ & 42334.822 & $5 / 2$ & $\mathrm{z}^{6} \mathrm{~F}^{0}$ \\
\hline & 2382.034 & 0.557 & 0.000 & $9 / 2$ & $a^{6} \mathrm{D}$ & 41968.046 & $11 / 2$ & $\mathrm{z}^{6} \mathrm{~F}^{0}$ \\
\hline & 2373.733 & -0.469 & 0.000 & $9 / 2$ & $a^{6} \mathrm{D}$ & 42114.818 & $9 / 2$ & $\mathrm{z}^{6} \mathrm{~F}^{0}$ \\
\hline & 2366.864 & -3.357 & 0.000 & $9 / 2$ & $a^{6} \mathrm{D}$ & 42237.033 & $7 / 2$ & $\mathrm{z}^{6} \mathrm{~F}^{0}$ \\
\hline \multirow[t]{9}{*}{ Fe II (3) } & 2380.757 & -0.628 & 667.683 & $5 / 2$ & $a^{6} \mathrm{D}$ & 42658.224 & $7 / 2$ & $\mathrm{z}^{6} \mathrm{P}^{0}$ \\
\hline & 2364.825 & -0.344 & 384.790 & $7 / 2$ & $a^{6} \mathrm{D}$ & 42658.224 & $7 / 2$ & $\mathrm{z}^{6} \mathrm{P}^{0}$ \\
\hline & 2359.111 & -0.542 & 862.613 & $3 / 2$ & $a^{6} \mathrm{D}$ & 43238.586 & $5 / 2$ & $\mathrm{z}^{6} \mathrm{P}^{0}$ \\
\hline & 2348.300 & -0.248 & 667.683 & $5 / 2$ & $a^{6} \mathrm{D}$ & 43238.586 & $5 / 2$ & $\mathrm{z}^{6} \mathrm{P}^{0}$ \\
\hline & 2344.278 & -0.450 & 977.053 & $1 / 2$ & $a^{6} \mathrm{D}$ & 43620.957 & $3 / 2$ & $\mathrm{z}^{6} \mathrm{P}^{0}$ \\
\hline & 2343.495 & 0.112 & 0.000 & $9 / 2$ & $a^{6} \mathrm{D}$ & 42658.224 & $7 / 2$ & $\mathrm{z}^{6} \mathrm{P}^{0}$ \\
\hline & 2338.008 & -0.385 & 862.613 & $3 / 2$ & $a^{6} \mathrm{D}$ & 43620.957 & $3 / 2$ & $\mathrm{z}^{6} \mathrm{P}^{0}$ \\
\hline & 2332.798 & -0.191 & 384.790 & $7 / 2$ & $a^{6} \mathrm{D}$ & 43238.586 & $5 / 2$ & $\mathrm{z}^{6} \mathrm{P}^{0}$ \\
\hline & 2327.391 & -0.631 & 667.683 & $5 / 2$ & $a^{6} \mathrm{D}$ & 43620.957 & $3 / 2$ & $\mathrm{z}^{6} \mathrm{P}^{0}$ \\
\hline
\end{tabular}


E. Verdugo et al.: Understanding A-type supergiants. I.

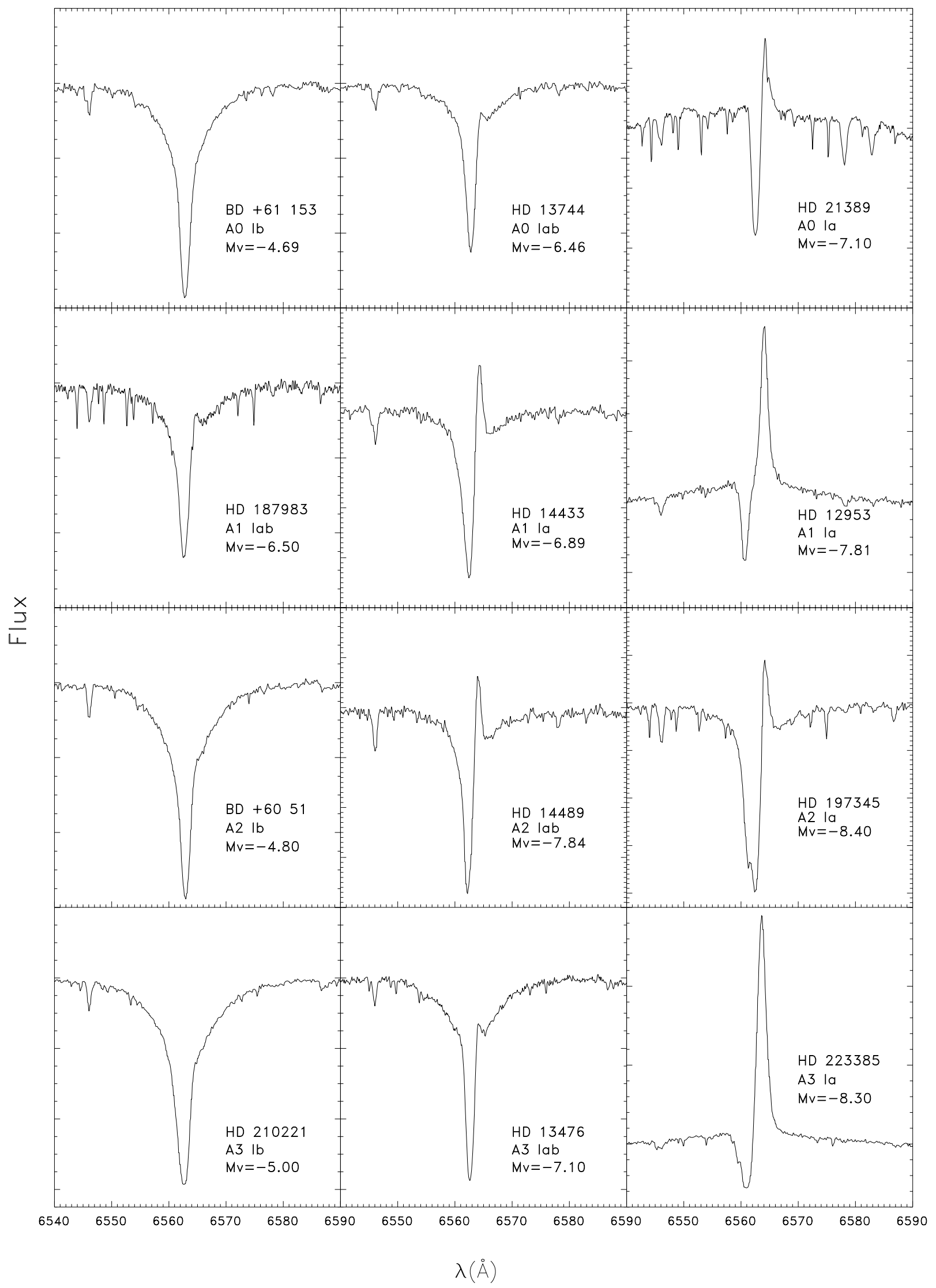

Fig. 4. Evolution of the $\mathrm{H} \alpha$ line with the luminosity of the stars 
the luminosity increases the initially symmetric absorption profiles become asymmetric with the violet wing being more extended than the red one up to a point in which a significant emission becomes visible and then the strength of this emission component increases steadily with the luminosity. This behaviour is particularly clear for stars with the same spectral type as it is well illustrated in Fig. 4.

Variations in $\mathrm{H} \alpha$ are observed in most of the A-supergiants. $\mathrm{H} \beta$ presents a symmetric absorption profile in all the A-supergiants except in HD 12953, HD 14535, HD21389, HD 223960 and HD 223385. The only star that shows any indication of asymmetry in $\mathrm{H} \gamma$ and $\mathrm{H} \delta$ is HD 223960. These stars also display the strongest variations in $\mathrm{H} \alpha$.

Ca II, Mg II (4481 ̊), Na I and He I.- These lines are photospheric (symmetric absorption profiles) in all sources, no wind effects have been detected. The Ca II $(\mathrm{H}$ and $\mathrm{K})$ and $\mathrm{Na} \mathrm{I} \mathrm{D}$ lines are strongly contaminated by the contribution from interstellar clouds. The line profiles show a complex structure with multiple components formed in absorbing regions at different velocities along the line of sight.

$\mathrm{Mg}$ II.- The UV resonance lines of $\mathrm{Mg}$ II are well known to be a sensitive indicator of wind in A-supergiants. Talavera \& Gómez de Castro (1987) described the profiles and divided A-supergiants into two groups depending on these resonance ultraviolet lines profiles. The less luminous stars did not show wind effects while the luminous ones showed the evidence of mass-loss. Our observations confirm this trend. The most luminous A-supergiants present two different types of profiles characteristic of mass outflow. In some stars the Mg II lines are asymmetric with no emission feature and a sharp blue edge. In other stars the Mg II profiles are composed of several deep shortward shifted components. Variations are observed in many stars but the most spectacular profiles variations are observed in two low-luminosity stars: HD 46300 and HD 87737 where we can see the appearance and evolution of a shortward shifted component superimposed on the profile of the Mg II.

Fe II.- The Fe II spectrum of the stars showing evidence of mass-loss in $\mathrm{H} \alpha$ is characterized by the presence of blue-shifted discrete absorption components. However not all the stars in this group present this behaviour. There are several stars whose Fe II lines are asymmetric and only slightly shortward shifted and other stars which present perfectly symmetric absorption lines. We have searched for variable components in the Fe II lines and we have detected these variations in the spectra of the most luminous stars.

Acknowledgements. We wish to thank Dr. A. Kaufer for having kindly provided unpublished optical data. We also thank the staff at VILSPA, La Palma, Calar Alto and Pic Du Midi observatories for the kind assistance during the observations. This work was partially supported by DGICYT PB93-491.

\section{References}

Abbott D.C., 1978, ApJ 225, 893

Achmad L., Lamers H.J.G.L.M., Pasquini L., 1997, A\&A 320, 196

Baudrand J., Böhm T., 1992, A\&A 259, 711

Bouw G.D., 1981, PASP 93, 45

Cassinelli J.P., Castor J.I., Lamers H.J.G.L.M., 1978, PASP 90, 496

Cananzi K., Augarde R., Lequeux J., 1993, A\&AS 101, 599

Fernie J.D., 1983, ApJS 52, 7

Garmany C.D., Stencel R.E., 1992, A\&AS 94, 211

Groenewegen M.A.T., Lamers H.J.G.L.M., 1991, A\&A 243, 249

Hensberge H., Lamers H.J.G.L.M, de Loore C., Bruhweiler F.C., 1982, A\&A 106, 137

Humphreys R.M., 1978, ApJS 38, 309

Kaltcheva N.T., Georgiev L.N., 1994, MNRAS 269, 289

Kunasz P.B., Morrison N.D., 1982, ApJ 263, 226

Kurucz R.L., Peytremann E., 1975, Smithsonian Astrophys., Obs. Spec. Rept. No. 362.

Kudritzki R.P., Springmann U., Puls J., Pauldrach A.W.A., Lennon M., 1997, in 2nd Boulder-Munich Workshop, ASP Conf., I. Howarth (ed.), p. 131

Lamers H.J.G.L.M., Snow T.P., Lindholm D.M., 1995, ApJ 455,269

Lamers H.J.G.L.M., Stalio R., Kondo Y., 1978, ApJ 223, 207

Lamers H.J.G.L.M., Snow T.P., 1978, ApJ 219, 504

McCarthy J.K., Kudritzki R.P., Lennon D.J., Venn K.A., Puls J., 1997, ApJ 482, 757

Middelburg F., 1981, IHAP Users Manual

Owocki S.P., 1992, in The Atmospheres of Early Type Stars, U. Heber \& C.S. Jeffery (eds.). Berlin: Springer-Verlag, p. 393

Praderie F., Talavera A., Lamers H.J.G.L.M., 1980, A\&A 86, 271

Rosendhal J.D., 1973, ApJ 186, 909

Stothers R.B., 1991, ApJ 383, 820

Talavera A., Gómez de Castro A.I., 1987, A\&A 181, 300

Underhill A.B., Doazan V., 1982, B stars with and without emission lines, NASA SP-456

Verdugo E., Talavera A., Gómez de Castro A.I., 1999, A\&A (in press) (Paper II) 